\title{
The mental health and
} wellbeing of medical

\section{students-A case study reflection}

Received: 06 June, 2020

Accepted: 20 June, 2020

Published: 22 June, 2020

*Corresponding author: Arunpreet Sahota, Department of Healthcare of Older People, QMC, Nottingham University Hospitals NHS Trust, Nottingham NG7 2UH, UK, E-mail: Opinder.Sahota@nuh.nhs.uk

https://www.peertechz.com

Check for updates

\section{Arunpreet Sahota*}

Department of Healthcare of Older People, QMC, Nottingham University Hospitals NHS Trust,

Nottingham NG7 2UH, UK

\section{Abstract}

Introduction: Depression is one of the most commonly diagnosed mental disorders among adults, previously seen as an acute and self-limiting illness, but is now recognised as a chronic, lifelong illness. The importance of mental health and wellbeing has been recognised among young adults and moreover healthcare professionals.

Interviewing a patient with chronic anxiety and depression, I reflect how these relate to the published literature relating to the metal health and wellbeing of medical students.

Methods: Interviewing a patient suffering with chronic anxiety and depressive illness, I highlight a number of areas I found thought provoking and review the published literature relating to mental health and wellbeing of medical students.

Results: The prevalence of depression or depressive symptoms in medical students is around $27.2 \%$ internationally, with suicidal ideation in approximately $11.1 \%$. The prevalence of anxiety is much higher, $33.8 \%$, most prevalent among medical students from the Middle East and Asia. Furthermore, medical students have a significantly higher prevalence of anxiety related symptoms compared with other non-medical students. Most worryingly two out of three medical students with generalised anxiety symptoms and one in two with depressive symptoms do not seek medical or psychological care. Mindfulness-based interventions decrease stress, anxiety, and depression and improve mindfulness, mood, self-efficacy, and empathy in health care students.

Discussion: There is a high prevalence of anxiety and depression amongst medical students and in those with anxiety symptoms alone, the risk of developing other mental health symptoms long-term is high. Medical student mental health and wellbeing has been recognised by the British Medical Association and proposal to include mental health awareness and promotion of self-care practices as part of the core curriculum. There are many self-help interventions that can help to reduce general anxiety symptoms and medical students should be more encouraged to take part in university societies, and extracurricular activities.

\section{The mental health and wellbeing of medical students-A case study reflection}

Depression is one of the most commonly diagnosed mental disorders among adults. Our understanding of the course and nature of depression has changed significantly in the last 15 years. Depression was previously seen as an acute and selflimiting illness, but is now recognised as a chronic, lifelong illness. The prevalence of depression is of concern, leading to significant patient morbidity, increased mortality and substantial costs to both health and social care [1].
This case report, follows a series of on line interviews with Joanna (an alias for confidentiality purposes), a 53 year old, university educated, part time accountant, highlighting a number of areas I found thought provoking and the associated reflective mental health and wellbeing of medical students in general.

\section{Is depression common in medical students?}

Joanna was first diagnosed with chronic depression in her early teenage years and battled with this throughout most of her adulthood. Studies have shown that upto $50 \%$ 
of those who recover from a first episode of depression have one or more additional episodes in their lifetime, and approximately $80 \%$ of those with a history of two episodes having another recurrence [2]. Once a first episode has occurred, recurrent episodes will usually begin within five years of the initial episode, with five to nine separate depressive episodes in their lifetime [3,4].This correlates positively with Joanna, who has already had four episodes. Joanna revealed that she attempted to take her own life last year, which took me by complete surprise, and it was something that I was not prepared for at all. This correlates with published research. A recent systematic review which included 28 publications, found that factors that significantly increase the risk of suicide, include: male gender (OR=1.76, 95\% $\mathrm{CI}=1.08-2.86)$, family history of psychiatric disorder ( $\mathrm{OR}=1.41$, 95\% CI=1.00-1.97), previous attempted suicide (OR=4.84, 95\% $\mathrm{CI}=3.26-7.20)$, more severe depression ( $\mathrm{OR}=2.20,95 \%$ $\mathrm{CI}=1.05-4.60)$, hopelessness $(\mathrm{OR}=2.20,95 \% \mathrm{CI}=1.49-3.23)$ and comorbid disorders, including anxiety $(\mathrm{OR}=1.59,95 \% \mathrm{CI}=1.03-$ 2.45) and misuse of alcohol and drugs ( $\mathrm{OR}=2.17,95 \% \mathrm{CI}=1.77-$ 2.66) [5].

We often read in the media about doctors taking their own life, which provoked me to reflect and research. A recent systematic review which included 167 cross-sectional studies [n= 116 628] and 16 longitudinal studies [ $n=5728$ ] from 43 countries showed that the overall pooled crude prevalence of depression or depressive symptoms in medical students was $27.2 \%$ (37 933/122 356 individuals; $95 \%$ CI, $24.7 \%$ to $29.9 \%$, I2 $=98.9 \%)$. In the 9 longitudinal studies that assessed depressive symptoms before and during medical school [ $n=2432$ ], the median absolute increase in symptoms was $13.5 \%$ (range, $0.6 \%$ to $35.3 \%$ ). The percentage of medical students screening positive for depression who sought psychiatric treatment was only $15.7 \%$ (110/954 individuals; $95 \%$ CI, $10.2 \%$ to $23.4 \%$, I2 = $70.1 \%)$. Suicidal ideation prevalence data were extracted from 24 cross-sectional studies $(n=21002$ ] from 15 countries and the overall pooled crude prevalence of suicidal ideation was $11.1 \%(2043 / 21002$ individuals; 95\% CI, 9.0\% $-13.7 \%$, I2 = $95.8 \%$ ) [6]. A survey of more than 4,300 doctors and medical students in the UK, showed more than a quarter $(27 \%)$ of respondents reported being diagnosed with a mental health condition at some point, and $40 \%$ of respondents reported currently suffering from a broader range of psychological and emotional conditions [7].

At the British Medical Association's (BMA) annual representative meeting in Brighton, UK (2019), members passed a motion calling for more research into the types of mental health issues experienced by medical students and to improve services available to them. The motion further asks that mental health awareness and promotion of self-care practices are made a core part of the curriculum, and that student health services should provide extended opening hours for those studying medicine, who are often unable to comply with a 9-to-5 timetable.

\section{Are symptoms of anxiety related to depressive symp- toms and is this common in medical students?}

Most people think of symptoms of depression related to continuous low mood or sadness, feeling hopeless and helpless, having low self-esteem, feeling tearful, guilt-ridden, irritable and intolerant of others, having no motivation or interest in things, finding it difficult to make decisions, not getting any enjoyment out of life, feeling anxious or worried, having suicidal thoughts or thoughts of harming yourself [8]. Although Joanna described many of the traits above, she also described what she called her sixth sense, almost like an 'aura' and recognised the 'impending sense of doom'. She described this as symptoms of worry and anxiety, feeling anxious about her work as an accountant, 'how she would cope, how this affected her mental health', constant ruminations. She recognised this as being a consistent factor throughout her relapses, demonstrating a thorough understanding of oneself. She described how she will be aware of imminent relapse, complicated by feelings of complete isolation and unable to initiate self-management steps to pivot herself out of a severe depressive episode. She had previously worked full time for a reputable accountancy firm but had now resigned herself to part-time, self-employment.

Research studies have consistently documented extensive comorbidity between anxiety and depression [9]. Major depressive disorders co-occur substantially with anxiety disorder, at much higher rates than with other diagnostic categories, such as substance use disorder or impulse-control $[10,11]$. Moreover, anxiety co-occurring with depression has been shown to have negative implications beyond the impact of each individual disorder, including poorer prognosis, academic difficulties, suicide risk, lower quality of life, and worse treatment outcomes $[12,13]$. This clearly has significant implications for Joanna.

This provoked me to reflect about anxiety symptoms in medical students, which I know are common and clearly this is a precursor for other mental health issues either concurrently or developing them long-term. A recent systematic review which examined just over 40,000 medical students showed a prevalence rate of anxiety symptoms of $33.8 \%$ (95\% Confidence Interval: 29.2-38.7\%), most prevalent among medical students from the Middle East and Asia [14]. Furthermore, in a study by de Sousa et al, medical students had a significantly higher prevalence of anxiety $(\mathrm{p}=0.034)$ compared with other students. More worryingly, 59.6\% $(\mathrm{n}=96)$ of the students with generalised anxiety symptoms and $46.4 \%(n=13)$ of the students with depressive symptoms did not seek medical or psychological care at that time [15].

\section{Do certain parental relationships increase the risk of developing depression in adolescence?}

Relatively early on I concluded that Joanna prides herself in being fiercely independent, conceding that although when she sees her mental state deteriorating, she disfavours reaching out to her family, apart from her sister, for support. Joanna talked about her traumatic and unstable parental relationship from childhood right through into her adolescence, which in turn has resulted in deterioration of her own relationship with her mother. A recent systematic review and meta-analysis concluded that parental factors which include less warmth, 
more inter-parental conflict and over-involvement increased risk for both depression and anxiety in adolescents [16]. This is extremely relevant, Joanna told me herself that this was 'the dominant and threatening thought over the Christmas period'. It was clear to see that although a fiercely independent and strong woman, significant unresolved childhood events can cripple an individual if left long enough, coming back to cause distress and influence thoughts in adulthood. My naïve preconception was that most people experience stable family networks, from childhood onward, and always have one to turn to in times of despondency. However, in reality it's much the opposite, this is something that I took for granted, and I wouldn't have gained the insight if I was not able to talk to Joanna in this way.

On reflection and going forward, I will be considerate in asking patients if they have a family network that they can turn to for support and love, when experiencing something as debilitating as mental illness. Interestingly, although I could find no published studies, talking to fellow medical students, many felt 'parental over-involvement' is a common theme amongst students and whether this correlates with higher rates of anxiety in medical students requires further evaluation.

\section{Are there any intervention to support anxiety for medi- cal students?}

There are a number of self-help interventions that have been shown to help reduce general anxiety symptoms, which include regular exercise, breathing techniques to help you learn to relax, avoiding stimulants (alcohol, smoking caffeine), joining support groups and more specialist online Cognitive Behavioural Therapy (CBT) [17]. When I discussed these with Joanna, she talked about a series of simple breathing exercises that she had been taught to help her, allowing her to focus on being present in that moment, which she found particularly helpful, and suggested this might be helpful for medical students too. Mindfulness, the process by which one attends to present-moment sensations, thoughts, emotions and experiences in a non-judgmental manner [18] has been reported to exert beneficial effects on health and well-being, both in non-clinical $[19,20]$ and clinical [21]. settings and lower the rates of depression and anxiety [22-24]. More specific to medical students, a recent systematic review, which included 19 studies (1815 participants), a meta-analysis was performed evaluating the effect of mindfulness training on mindfulness, anxiety, depression, stress, mood, self-efficacy, and empathy on health profession students. The authors concluded that mindfulness-based interventions decreased stress, anxiety, and depression and improve mindfulness, mood, self-efficacy, and empathy and thus should be integrated into health professional training programs [25]. The department of health website offers a really easy to follow webinar by Dr Chris Williams [17].

In addition to significantly lowering causes of mortality, regular exercise and physical activity lowers prevalence of chronic disease[s]. There is a strong evidence to support that $2-2.5$ h of moderate- to high-intensity exercise per week is sufficient to reduce one's risk for the occurrence of a chronic disease[s]. Numerous epidemiological studies have shown that exercise improves one's self-esteem, and a sense of wellbeing. Individuals who exercise regularly exhibit slower rates of agerelated memory and cognitive decline in comparison to those who are more sedentary. Such observations have provided the basis for using exercise to improve memory and cognition. Adults who engage in regular physical activity experience fewer depressive and anxiety symptoms, thus supporting the notion that exercise offers a protective effect against the development of mental disorders [26]. From talking to Joanna about her medical and social history, exercise was not an integral part of her day to day routine. I concurred that the next best intervention, was to encourage Joanna to undertake a form of physical activity. Unfortunately, when I suggested this, Joanna very bravely admitted that she has struggled a lot with body image, exercising in groups was an inconceivable task that she has attempted to address for many years in the past with no success. Reading this I felt upset and guilty that I had triggered a sensitive matter, and bringing exercise up caused Joanna to 'feel teary'.

Joanna then went on to tell me that she feels that she is more suited toward a more creative outlook, describing how she wishes to join a $55^{+}$painting group next year, as this allows her to express herself without superseding the limits of her insecurities. This made me feel like I wasn't really helping, Joanna had proposed her own lifestyle management plans instead of us suggesting a new intervention! However, in reflection, it is important to realise that some patients may already be very proactive in the management of their own mental health, and like Joanna, manage to lead a relatively symptom free life, because of using interventions that work for the individual. Indeed, singing and painting interventions have been shown to reduce pain and improve mood, quality of life, and cognition, with differential effects of painting for depression and singing for memory performance [26].

In reflection I think it is highly important to recognise that although as a healthcare professional, it is paramount to explore potential lifestyle modifications first, sometimes there are more deep-seated reasons as to why patients may not feel comfortable to pursue particular interventions. The best approach is to ask the patient what they think is the next best step, allowing them to lead the consultation, and as a doctor being there to offer guidance and support, rather than simply ticking a checklist of options explored. There is no blueprint when it comes to treating mental health, and every patient should be treated on an individual basis. In Leicester University alone there are over 250 Student Groups - from Hiking to Book Club, Erasmus and Exchange to eSports, Basketball to Volleyball. They even advertise that 'if there's nothing you are interested in - you can always start your own!' Thus the importance of this is being involved with something rather than noting to help relieve the everyday stresses of medical school teaching.

\section{Summary}

In conclusion, meeting Joanna has been an invaluable experience, allowing me to reflect on how her symptoms 
relate to the mental health and wellbeing of medical students. There is a high prevalence of anxiety and depression amongst medical students and in those with anxiety symptoms alone, the risk of developing other mental health symptoms longterm is high. Medical student mental health and wellbeing has been recognised by the BMA and proposal to include mental health awareness and promotion of self-care practices as part of the core curriculum, and that student health services should provide extended opening hours for those studying medicine, who are often unable to comply with a 9-to-5 timetable. Most of all however, there are many simple elf help interventions that can help to reduce general anxiety symptoms. Medical students should be more encouraged to take part in university societies, and extracurricular activities.

\section{References}

1. Johnson J, Weissman M, Klerman GL (1992) Service utilization and social morbidity associated with depressive symptoms in the community. JAMA 267: 1478-1483. Link: https://bit.ly/2Yktj5G

2. Kupfer DJ, Frank E, Wamhoff J (1996) Mood disorders: Update on prevention of recurrence. In: Mundt C, Goldstein MJ, editors. Interpersonal factors in the origin and course of affective disorders. London, England: Gaskell/Royal College of Psychiatrists 289-302.

3. Kessler RC, Walters EE (1998) Epidemiology of DSM-III-R major depression and minor depression among adolescents and young adults in the national comorbidity survey. Depressi Anxiety 7: 3-14. Link: https://bit.ly/3hOztCO

4. Kessler RC, Zhao S, Blazer DG, Swartz M (1997) Prevalence, correlates and course of minor depression and major depression in the national comorbidity survey. J Affect Disord 45: 19-30. Link: https://bit.ly/2V5MYod

5. Hawton K, Comabella CC, Haw C, Saunders K (2013) Risk Factors for Suicide in Individuals With Depression: A Systematic Review. J Affect Disord 147: 17 28. Link: https://bit.ly/2AWEQ2/

6. Rotenstein LS, Ramos MA, Torre M (2016) Prevalence of Depression, Depressive Symptoms, and Suicidal Ideation Among Medical Students. A Systematic Review and Meta-Analysis. JAMA 316: 2214-2236. Link: https://bit.ly/2AWUISu

7. Serious mental health crisis among doctors and medical students revealed in BMA report. BMA. Link: https://bit.ly/3dqewe2

8. Link: https://bit.ly/3fLOJP2

9. Maser JD, Cloninger CR (1990) Comorbidity of mood and anxiety disorders. Washington, D.C.: American Psychiatric Association. Link: https://bit.ly/3fJgBDy

10. Kessler RC, Chiu WT, Demler O, Walters EE (2005) Prevalence, Severity, and Comorbidity of 12-Month DSM-IV Disorders in the National Comorbidity Survey Replication. Arch Gen Psychiatry 62: 617-627. Link: https://bit.ly/2Bxcvzm

6. Kessler RC, Merikangas KR, Wang PS (2007) Prevalence, comorbidity, and service utilization for mood disorders in the United States at the beginning of the twenty-first century. Annu Rev Clin Psychol 3: 137-158. Link: https://bit.ly/2YVt2p4

7. Rush AJ, Zimmerman M, Wisniewski SR, Fava M, Hollon SD, et al. (2005) Comorbid psychiatric disorders in depressed outpatients: Demographic and clinical features. J Affect Disord 87: 43-55. Link: https://bit.ly/3fKjhRh
8. Young JF, Mufson L, Davies M (2006) Impact of Comorbid Anxiety in an Effectiveness Study of Interpersonal Psychotherapy for Depressed Adolescents. J Am Acad Child Adolesc Psychiatry 45: 904-912. Link: https://bit.ly/370eATT

9. Quek TT, Tam WWS, Tran BX, Zhang M, Zhang Z, et al. (2019) The Globa Prevalence of Anxiety Among Medical Students: A Meta-Analysis. Int J Environ Res Public Health 16: 2735. Link: https://bit.ly/2Z0jitP

10. de Sousa JM, Moreira CA, Telles-Correia D (2018) Anxiety, Depression and Academic Performance: A Study Amongst Portuguese Medical Students Versus Non-Medical Students. Acta Med Port 31: 454-462. Link: https://bit.ly/2Z2NAfw

11. Yap MBH, Pilkington PD, Ryan SM, et al. (2014) Parental factors associated with depression and anxiety in young people: A systematic review and metaanalysis. J Affect Disord 156: 8-23. Link: https://bit.ly/3hRWDYY

12. Link: https://bit.ly/2zPI86S .

13. Marlatt GA, Kristeller JL (1999) "Mindfulness and meditation," in Integrating Spirituality Into Treatment: Resources for Practitioners, ed. Miller W. R. (Washington: American Psychological Association) 67-84.

14. Tan LBG, Martin G (2016) Mind full or mindful: a report on mindfulness and psychological health in healthy adolescents. Int J Adolesc Youth 21: 64-74. Link: https://bit.ly/3hQXI8U

11. Demarzo M, Montero-Marin J, Puebla-Guedea M, Navarro-Gil M, HerreraMercadal P, et al. (2017) Efficacy of 8- and 4-session mindfulness-based interventions in a non-clinical population: a controlled study. Front Psychol 8 : 1343-1349. Link: https://bit.ly/2V3nKa0

12. Mitchell JT, McIntyre EM, English JS, Dennis MF, Beckham JC, et al. (2016) A pilot trial of mindfulness meditation training for ADHD in adulthood: impact on core symptoms, executive functioning, and emotion dysregulation. J Atten Disord 21: 1105-1120. Link: https://bit.ly/3enjCJt

13. Chu CS, Stubbs B, Chen TY, Tang CH, Li DJ, et al. (2018) The effectiveness of adjunct mindfulness-based intervention in treatment of bipolar disorder: a systematic review and meta-analysis. J Affect Disord 225: 234-245. Link: https://bit.ly/2ZOwApW

14. Desrosiers A, Vine V, Klemanski DH, Nolen-Hoeksema S (2013) Mindfulness and emotion regulation in depression and anxiety: common and distinmct mechanisms of action. Depress Anxiety 30: 654-661. Link: https://bit.ly/3fNXKqK

15. Tran US, Cebolla A, Glück TM, Soler J, Garcia-Campayo J, et al. (2014) The serenity of the meditating mind: a cross-cultural psychometric study on a two-factor higher order structure of mindfulness, its effects, and mechanisms related to mental health among experienced meditators. PLoS One 9: e110192. Link: https://bit.ly/2V3xf8Q

16. McConville J, McAleer R, Hahne A (2017) Mindfulness Training for Health Profession Students-The Effect of Mindfulness Training on Psychological WellBeing, Learning and Clinical Performance of Health Professional Students: A Systematic Review of Randomized and Non-randomized Controlled Trials. Explore 13: 26-45. Link: https://bit.ly/370yQVm

17. van Minnen A, Hendriks L, Olff M (2010) When do trauma experts choose exposure therapy for PTSD patients? A controlled study of therapist and patient factors. Behav Res Ther 48: 312-320. Link: https://bit.ly/3hRcXZZ

18. Pongan E, Tillmann, Leveque $Y$, Trombert B, Getenet JC, et al. (2017) Can Musical or Painting Interventions Improve Chronic Pain, Mood, Quality of Life, and Cognition in Patients? Evidence From a Randomized Controlled Trial. J Alzheimers Dis 60: 663-677. Link: https://bit.ly/2YjSOPL

Copyright: ( 2020 Sahota A. This is an open-access article distributed under the terms of the Creative Commons Attribution License, which permits unrestricted use, distribution, and reproduction in any medium, provided the original author and source are credited.

Citation: Sahota A (2020) The mental health and wellbeing of medical students-A case study reflection. Arch Depress Anxiety 6(1): 033-036. DOI: https://dx.doi.org/10.17352/2455-5460.000049 